\title{
Endoscopic Lung Volume Reduction with Endobronchial Valves in Patients with Severe Emphysema and Established Pulmonary Hypertension
}

\author{
Ralf Eberhardt ${ }^{\mathrm{a}}$ Vasiliki Gerovasili ${ }^{\mathrm{a}} \quad$ Konstantina Kontogianni ${ }^{\mathrm{a}}$ \\ Daniela Gompelmann ${ }^{a}$ Nicola Ehlken ${ }^{b}$ Felix J.F. Herth ${ }^{a}$ \\ Ekkehard Grünig $^{\text {b }}$ Christian Nagel ${ }^{b, c}$ \\ a Department of Pulmonology and Respiratory Care Medicine and ${ }^{b}$ Center for Pulmonary Hypertension, Thoraxklinik, \\ University of Heidelberg, Heidelberg, and ' Lung Center, Klinikum Mittelbaden, Baden-Baden, Germany
}

\section{Key Words}

Endoscopic lung volume reduction - Emphysema .

Pulmonary hypertension - Valve placement

\begin{abstract}
Background: One of the most common forms of pulmonary hypertension $(\mathrm{PH})$ is that associated with chronic obstructive pulmonary disease (COPD). So far, patients with severe emphysema and established PH have been excluded from endoscopic lung volume reduction (ELVR) therapy due to the risk of right heart decompensation. Objective: The aim of this pilot study was to evaluate the feasibility and efficacy of ELVR using one-way endobronchial valves (EBV) in this specific group of patients. Methods: We prospectively included 6 patients with COPD, severe heterogeneous emphysema, and established $\mathrm{PH}$ who underwent right heart catheterization and clinical assessments before and 90 days after ELVR with unilateral EBV placement. Results: This study was not powered to measure any statistical differences in endpoints. Ninety days after ELVR, the symptoms, lung function, and hemodynamics improved in 5 out of 6 patients ( 1 patient normalized and 1 slightly worsened). The mean hemodynamics improved from baseline to 90 days after ELVR as follows: mean pulmonary artery pressure, $-2.5 \pm 3.5 \mathrm{~mm} \mathrm{Hg}$;
\end{abstract}

pulmonary arterial wedge pressure, $-4.3 \pm 8.3 \mathrm{~mm} \mathrm{Hg}$; cardiac index, $+0.3 \pm 0.6 \mathrm{l} / \mathrm{min} / \mathrm{m}^{2}$, and 6 -min walk distance, $+59 \pm 99 \mathrm{~m}$. ELVR was performed without PH-related complications in all patients. Conclusion: To our knowledge, this is the first prospective, single-center pilot study to evaluate the feasibility and efficacy of ELVR in patients with established PH. ELVR was feasible and resulted in an improvement of clinical and hemodynamic parameters in 5 out of 6 patients. These results have to be further confirmed in largerscale controlled studies.

(c) 2014 S. Karger AG, Basel

\section{Introduction}

Chronic obstructive pulmonary disease (COPD) continues to be a leading cause of morbidity and is currently the third most common cause of mortality worldwide [1]. In most patients with severe COPD, chronic airflow limitation, lung emphysema with parenchymal destruction

R.E., D.G., F.H. and E.G. are affiliated to the Translational Lung Research Centre Heidelberg and they are members of the German Centre for Lung Research (DZL), Heidelberg, Germany.

\section{KARGER 125}

C 2014 S. Karger AG, Basel

0025-7931/14/0891-0041\$39.50/0

E-Mail karger@karger.com

www.karger.com/res
Prof. Dr. med. Ralf Eberhardt, MD

Department of Pulmonology and Respiratory Care Medicine

Thoraxklinic, University of Heidelberg

Amalienstrasse 5, DE-69126 Heidelberg (Germany)

E-Mail ralf.eberhardt@med.uni-heidelberg.de 
and the development of air bullae also occur [2-5]. Manifest pulmonary hypertension $(\mathrm{PH})$, defined as a mean pulmonary artery pressure (mPAP) at rest $\geq 25 \mathrm{~mm} \mathrm{Hg}$ [6], is another complication and occurs frequently in patients with COPD as well as in lung emphysema. $\mathrm{PH}$ associated with chronic parenchymal lung diseases, including COPD, is one of the most common forms of $\mathrm{PH}$ [7-9]. In some series the prevalence of $\mathrm{PH}$ has been up to 50\% [10-13]. In the majority of these cases, the $\mathrm{PH}$ has been only mild, with mildly elevated pulmonary pressures and pulmonary vascular resistance (PVR) and a preserved cardiac output (CO) $[8,9]$. The pathophysiology of $\mathrm{PH}$ in $\mathrm{COPD}$ is complex and most likely multifactorial [13].

The therapeutic options for COPD patients with severe emphysema are limited. Lung volume reduction surgery (LVRS) has been performed as treatment in selected cases, but the referral of patients has been severely influenced by the marked perioperative morbidity and mortality [1416]. Less invasive techniques have been developed with the aim of improving patients' pulmonary function, symptoms, and quality of life (QoL) [17]. Among them, the one most commonly used is the endoscopic placement of oneway endobronchial valves (EBV) [18-21]. So far patients with severe emphysema and established $\mathrm{PH}$ have been excluded from LVRS as well as from endoscopic lung volume reduction (ELVR) therapy. Whether one-way EBV placement influences the severity of $\mathrm{PH}$ in patients with severe emphysema and $\mathrm{PH}$ has yet to be elucidated.

We hypothesized that ELVR with valves is feasible in patients with severe emphysema and manifest $\mathrm{PH}$. This study was designed as a prospective pilot study, with the primary endpoint being the feasibility of ELVR in $\mathrm{PH}$ as assessed based on changes in lung function parameters. Secondary endpoints were changes in hemodynamic parameters, exercise capacity, and QoL.

\section{Materials and Methods}

This prospective study investigated patients with severe COPD, heterogeneous emphysema, and manifest $\mathrm{PH}$ (WHO functional class III-IV) who fulfilled the indication criteria for EVLR therapy. All patients gave written informed consent for participation in this study, which was approved by the Ethics Committee of the University of Heidelberg (clinical trial registration No. NCT01393379).

Patients older than 30 years were included (table 1). All patients received optimal medical treatment for COPD according to Global Initiative for Chronic Obstructive Lung Disease guidelines [22]. In all cases, the COPD had to be stable without exacerbations within the last 8 weeks, steroids had to have been used in doses of less than $20 \mathrm{mg}$ of prednisone or equivalent per day, and a nonsmoking status had to have been present of more than 4 months. ELVR with place-
Table 1. Main inclusion criteria

\section{Inclusion criteria}

Written consent signed by patients

Men or women, aged $>30$ years

Clinical indication of treatment with ELVR

PH group 3.1 according to the Dana Point Classification, 2008

Severe lung emphysema with

$\mathrm{FEV}_{1}<45 \%$

$\mathrm{RV}>150 \%$

TLC $>100 \%$

Optimal medical treatment according to the latest GOLD guidelines

Heterogeneous lung emphysema

Established by thin-section MSCT

Images postprocessing using an automated software analysis

(YACTA) enhancing the emphysema distribution

Confirmed by the use of perfusion scintigraphy

Stable COPD

No exacerbations in the last 8 weeks

Steroids used in doses $<20 \mathrm{mg}$ of prednisone equivalent

Ex-smokers

Duration of abstinence $>4$ months

$\mathrm{CoHb}<2.5 \%$

$\mathrm{PH}$ diagnosed by means of RHC $\mathrm{mPAP} \geq 25 \mathrm{~mm} \mathrm{Hg}$

GOLD = Global Initiative for Chronic Obstructive Lung Disease; HRCT = high-resolution computer tomography; $\mathrm{CoHb}=$ carboxyhemoglobin; $\mathrm{RHC}=$ right heart catheterization.

ment of EBV was indicated because of severe emphysema [forced expiratory volume in $1 \mathrm{~s}\left(\mathrm{FEV}_{1}\right)<45 \%$, residual volume $(\mathrm{RV})>150 \%$, total lung capacity $>100 \%$ ] with progressively deteriorating dyspnea and the presence of at least one complete interlobar fissure upon baseline assessment on thin-section multislice computed tomography (MSCT) [17, 23]. The heterogeneity and distribution of the emphysema were visually determined by nonenhanced MSCT and the images were postprocessed with the help of an automated software analysis $\left(\right.$ YACTA $^{\circledR}$ ), enhancing the emphysema distribution, and confirmed by the use of perfusion scintigraphy [24, 25].

The diagnosis of $\mathrm{PH}$ was performed according to current guidelines $[6,26]$. All patients underwent a detailed clinical workup within 4 weeks before the ELVR, including a medical history, a physical examination, an electrocardiogram, a 2-D echocardiography at rest, pulmonary function tests, arterial blood gases, a chest $\mathrm{X}$-ray, the 6-min walk distance (6MWD) under standardized conditions, the dyspnea score [using modified Medical Research Council (mMRC) criteria, with 0 representing dyspnea with strenuous exercise and 4 representing dyspnea with breathlessness when dressing], QoL as established by the St. George Respiratory Questionnaire (SGRQ; scores from 0 to 100, higher scores represent more limitations) [27, 28], and right heart catheterization (RHC). Left heart catheterization was performed in all patients with suspected left heart diseases and when clinically indicated.

Between baseline and 90 days, no changes in medical treatment were observed, no cardiac interventions were performed, and the
Eberhardt et al. 
patients did not receive any rehabilitation, with the exception of one patient who will be described in detail in Adverse Events. None of the patients received targeted medical treatment for $\mathrm{PH}$.

Follow-Up Assessment

Patients were assessed at baseline and after 90 days using the same parameters as at baseline. Radiologic and hemodynamic monitoring was performed using a chest X-ray at baseline and after 30 and 90 days, and an MSCT scan and RHC were performed at baseline and after 90 days. Significant complications (severe hemorrhage, pneumothorax, or death) were recorded prospectively.

\section{Endoscopic Placement of One-Way EBV}

Patients underwent unilateral EBV placement with complete occlusion of the lobe mostly affected by emphysema. Each procedure was performed by experienced investigators (R.E. and D.G.) under general anesthesia with a combination of rigid and flexible bronchoscopy as per hospital standards. A Chartis measurement was not performed during the procedure. The presence of at least one complete fissure had been previously assessed with MSCT. EBV (Zephyr; Pulmonx, USA) were placed unilaterally in segmental or subsegmental bronchi on the basis of individual anatomy in order to completely isolate the targeted lobe. According to our standard protocol, all patients received a postintervention antibiotic prophylaxis and a chest radiograph within $24 \mathrm{~h}$ and remained in hospital for an average of 4 days for further observation.

\section{Right Heart Catheterization}

RHC was performed at rest in a supine position using the transjugular approach with an 8-Fr introducer set (MXI100; Medex, UK). Catheterization was done using triple-lumen 7-Fr Swan-Ganz thermodilution catheters (ref. 131F7; Edwards Lifesciences LLC, Irvine, Calif., USA). Pressures were continuously recorded and measured at the end of expiration. The following variables were recorded during RHC using a hemodynamic recording system by Marquette Hellige/GE Medical Systems: pulmonary arterial pressure (PAP; systolic, diastolic, and mean), right atrial pressure (RAP), pulmonary arterial wedge pressure (PAWP), and right ventricular pressure (RVP). The CO was measured at least 3 times by thermodilution. Values were considered valid when a variation of less than $10 \%$ between the measured values occurred. Superior vena cava, right atrial, right ventricular, pulmonary arterial, and systemic capillary blood oxygen saturations were determined at rest to detect and exclude systemic-to-pulmonary shunts as a cause of elevated PA pressures. The PVR and the cardiac index (CI) were calculated. The zero reference point for pressure recordings was set at the level of the right atrium on the midaxillary line. All examinations and measurements were performed by the same experienced team.

\section{Transthoracic Doppler Echocardiography}

Two-dimensional and color flow-guided continuous-wave Doppler echocardiographic recordings were obtained by experienced cardiac sonographers (E.G. and C.N.) at baseline and 90 days after the procedure using $2.5-\mathrm{MHz}$ Duplex probes and conventional equipment (Vivid 7; GE Healthcare, Milwaukee, Wisc., USA). The systolic PAP (PASP) was estimated from peak tricuspid regurgitation jet velocities according to the equation: PASP = $4(\mathrm{~V})^{2}+\mathrm{RAP}$, where $\mathrm{V}$ is the peak velocity (in $\mathrm{m} / \mathrm{s}$ ) of the tricuspid regurgitant jet [29]. For all calculations, the mean value of at least 3 tricuspid regurgitant jet velocity measurements was used. RAP

ELVR with EBV in Patients with Severe Emphysema and Established PH was estimated from the characteristics of the inferior vena cava. If it was $<20 \mathrm{~mm}$ in diameter and decreased during inspiration we added $5 \mathrm{~mm} \mathrm{Hg}$, and if it was $\geq 20 \mathrm{~mm}$ in diameter we added 10 $\mathrm{mm} \mathrm{Hg}$. Right atrial and right ventricular areas were measured by planimetry in the 4-chamber view. For all calculations, a mean value of at least 3 planimetric measurements was used.

\section{Feasibility Endpoints}

Feasibility was assessed by changes in pulmonary function tests after ELVR, which was the primary endpoint of this study. Secondary endpoints included differences in RHC parameters, exercise capacity assessed using the 6MWD, QoL assessed using the SGRQ, and perception of dyspnea assessed by mMRC. Significant adverse events were also recorded.

\section{Statistical Analysis}

This pilot study is of an explorative character to assess the tolerability and give first data on the efficacy of ELVR in patients with $\mathrm{PH}$ and severe emphysema. Descriptive statistics were used to summarize changes in quantitative variables. Data are given as absolute values for each patient and for differences between baseline and 90 -day follow-up values and as means \pm SD for the two different time points and for differences.

All analyses were performed using IBM SPSS 20 (SPSS Statistics v20; IBM Corporation, Somers, N.Y., USA).

\section{Results}

\section{Study Population}

During the study period (April 2009 to April 2012), we prospectively included 8 patients diagnosed with COPD and lung emphysema eligible for ELVR and with manifest $\mathrm{PH}$. One patient was excluded because he had already received $\mathrm{PAH}$-targeted treatment and one patient was lost to follow-up after his baseline assessment. This patient tolerated the baseline assessment and the ELVR procedure without any complications, adverse events, or signs of clinical worsening. However, he did not attend his follow-up visit after 90 days. The general physician of the patient was contacted and reported the patient's unexpected death 4 months after ELVR due to severe pneumonia. The hemodynamics of the patient at baseline showed a manifest $\mathrm{PH}$ which was more severe than that of the other study patients, with an mPAP of $47 \mathrm{~mm} \mathrm{Hg}$, a $\mathrm{CO}$ of $4.7 \mathrm{l} / \mathrm{min}$, a CI of $2.5 \mathrm{l} / \mathrm{min} / \mathrm{m}^{2}$, a PAWP of $15 \mathrm{~mm} \mathrm{Hg}$, and a PVR of 561 dynes $\cdot \mathrm{s} \cdot \mathrm{cm}^{-5}$. The right atrial area was $20 \mathrm{~cm}^{2}$, the right ventricular area was $34 \mathrm{~cm}^{2}$, and the TAPSE was $1.7 \mathrm{~cm}$. It cannot be excluded that his sudden unexpected death was also due to a clinical worsening of his severe $\mathrm{PH}$. Thus, the final study group consisted of 6 patients (table 2). All patients were male (mean age $72 \pm 5$ years) and ex-smokers for at least 4 months. 





Fig. 1. Hemodynamic parameters at baseline and after ELVR. The change in hemodynamic parameters from baseline to the 90-day follow-up is shown. The mean change is shown as a solid back line \pm SD. Hemodynamic parameters improved in all patients, except in patient 2 who showed a slight worsening in all parameters. a mPAP (mm Hg). b PAWP (mm Hg). c CO (l/min). d CI $\left(1 / \mathrm{min} / \mathrm{m}^{2}\right)$.



\section{ELVR Procedure}

All patients were treated unilaterally. Three patients underwent ELVR with valves in the right upper lobe ( 1 in the left upper lobe and 2 in the left lower lobe). Lung volume reduction was documented radiologically in 5 patients. Specifically, patient 1 did not show a lung volume reduction on MSCT at the 90-day follow-up. As for the rest of the patients, a significant volume reduction of the treated lobe was evident in patients $2-5$ and a minimal volume reduction of the treated lobe was noted in patient 6 . The lung function and hemodynamic parameters are included in table 2.

\section{Changes in Hemodynamic Parameters after ELVR}

At baseline, the PH was mild in all 6 patients with mildly elevated mPAP and mean PVR and preserved right ventricular pump function. The mean PAWP was $<15 \mathrm{~mm} \mathrm{Hg}$ except in 2 patients. None of the patients showed signs of a relevant left heart disease. After 90 days, 5 out of 6 patients had an improvement in their hemodynamics. In patient 5 , the mean PAP even normalized from 27 to $22 \mathrm{~mm} \mathrm{Hg}$ after ELVR. In patient 2, the hemodynamics and right ventricular function slightly decreased (mPAP from 28 to $31 \mathrm{~mm} \mathrm{Hg}$, CO from 5.7 to $4.9 \mathrm{l} / \mathrm{min}$; table 2; fig. 1).

ELVR with EBV in Patients with Severe Emphysema and Established $\mathrm{PH}$
Overall, the mPAP decreased by $2.5 \mathrm{~mm} \mathrm{Hg}$ from $31 \pm 6.5$ to $28.5 \pm 5.1 \mathrm{~mm} \mathrm{Hg}$ while the PAWP dropped by $4.3 \mathrm{~mm} \mathrm{Hg}$ from $13.2 \pm 7.5$ to $8.8 \pm 2 \mathrm{~mm} \mathrm{Hg}$. The decrease in mPAP seemed to be mostly associated with a decrease in diastolic PAP $(-3.7 \pm 4.6 \mathrm{~mm} \mathrm{Hg})$, whereas the PASP showed a mild increase $(1.3 \pm 7.1 \mathrm{~mm} \mathrm{Hg})$. The mean PVR decreased in 4 out of 6 patients, with a mean value from $297 \pm 120$ to $282 \pm 93$ dynes $\cdot \mathrm{s} \cdot \mathrm{cm}^{-5}$. The mixed venous oxygen saturation measured in the pulmonary artery remained stable (from $67.2 \pm 6$ to $67.2 \pm 5.2 \%)$.

Overall, the mean right ventricular function improved after ELVR, with an increase in mean CI of $0.3 \mathrm{l} / \mathrm{min} / \mathrm{m}^{2}$ and an increase in mean CO of $0.61 / \mathrm{min}$.

The planimetric echocardiographic measurements of right atrial and right ventricular size showed an improvement in 5 out of 6 patients; 2 patients (No. 1 and 3 ) had a decrease in right atrial area but an increase in right ventricular area. The mean right atrial area decreased from $20.8 \pm 4.3$ to $16.1 \pm 3.3 \mathrm{~cm}^{2}$. This decrease in right atrial size was present in 5 out of 6 patients; patient 6 showed no change in right atrial size. TAPSE was within the normal range $(>1.8 \mathrm{~cm})[28]$ at baseline and 90 days after ELVR. All data are summarized in table 2. 
Lung Function Tests, the 6MWD, and QoL

The FEV $\mathrm{F}_{1}$ showed an improvement in 4 out of 6 patients, with a mean increase of $0.2 \pm 0.3$ liters $(0.76 \pm$ 0.13 vs. $0.96 \pm 0.28$ liters). The mean predicted vital capacity increased by $7.5 \pm 15.3 \%$. The mean $6 \mathrm{MWD}$ improved by $58.8 \pm 98.8 \mathrm{~m}$ after ELVR, which was mainly attributed to a marked improvement of 210 and $109 \mathrm{~m}$ in 2 of the 6 patients, respectively. The walking distance of the other 3 patients showed no or only very mild changes without clinical relevance and decreased by $10 \mathrm{~m}$ in patient 2 .

Five of the 6 patients (patient No. 1, 3, and 6), who had improved in hemodynamic parameters, also showed improvement in QoL scores. The mean QoL as assessed using the SGRQ improved from $61 \pm 15$ to $43 \pm 22$ (lower scores means less limitations), as did the perception of dyspnea. The mMRC, which was assessed in 5 patients only (1 patient had missing data), improved from $3.2 \pm$ 0.8 to $2.4 \pm 1.3$.

\section{Adverse Events}

In all patients, no adverse events associated with $\mathrm{PH}$ occurred during or after ELVR. So, no signs of right heart failure were observed during or within 1 week after the procedure. No valves needed to be replaced or removed. One patient (patient No. 2) suffered from a pneumothorax within the ELVR procedure which was cured within 2 days after the insertion of a chest drain. The same patient had intermittent tachycardia after ELVR, which was controlled with short-duration $\beta$-blocker therapy. In one further patient, COPD exacerbation due to a respiratory infection occurred during the 3-month post-ELVR period. In patient 3, non-small cell lung cancer was detected at his 90-day follow-up visit. No valves needed to be removed or replaced.

\section{Discussion}

To our knowledge, this is the first prospective pilot study to evaluate the feasibility of ELVR in patients with severe COPD lung emphysema and concomitant PH. In $83 \%$ of patients, ELVR improved the symptoms, hemodynamics, lung function, and QoL parameters. ELVR with valves was feasible and tolerable by all patients without signs of worsening of pulmonary circulation or $\mathrm{PH}$ associated adverse events. Thus, this treatment may be an interesting new perspective for a selected COPD-PH patient group, which might merit validation in larger controlled studies.

\section{Feasibility of ELVR in These Patients}

So far, patients with COPD, severe lung emphysema, and manifest $\mathrm{PH}$ have been excluded from both LVRS [13] and ELVR [18] due to the concern of right heart failure and adverse effects on lung circulation. The results of this pilot study suggest that ELVR is feasible without imposing an extra burden or worsening the PH. Another main finding was that all patients improved after the intervention in terms of their pulmonary function as well as dyspnea perception and QoL without the occurrence of any clearly $\mathrm{PH}$-associated adverse events. Pneumothorax, which occurred in 1 of the 6 patients, is the most common complication of ELVR [20] and was not PH related. The same patient suffered from intermittent tachycardia which returned to a sinus rhythm with $\beta$-blocker therapy. One patient who died 4 months after ELVR was excluded from the analysis due to loss to follow-up and missing values after 3 months. The unexpected death of this patient who at baseline had a more severe $\mathrm{PH}$ compared to the included 6 patients was most unlikely related to the ELVR procedure itself. However, we cannot exclude that it was related not only to pneumonia but also to a worsening of $\mathrm{PH}$. This case reflects the general problem of $\mathrm{PH}$ in patients with lung disease, which is that it may be difficult or even impossible to differentiate if a patient is suffering from chronic lung disease with resulting $\mathrm{PH}$ or from $\mathrm{PAH}$ with concomitant but not causative chronic lung disease [30]. This case suggests that ELVR may be helpful in mild forms with $\mathrm{PH}$; it may, however, not be the appropriate treatment for patients with severe $\mathrm{PH}$ and lung emphysema.

\section{ELVR Improved Hemodynamic and Other Clinical Parameters}

The hemodynamic parameters, lung function, exercise capacity, and QoL improved, as mentioned previously, in the majority of patients. The mean increase in $\mathrm{FEV}_{1}$ after ELVR with valves was $26 \%$, which is more than the minimal clinically significant change [31]. The QoL improved by 17 points, which is more than the reported minimal clinically significant difference of 4 points and corresponds to a very efficacious treatment [32]. In contrast to lung function and QoL, there is no minimal clinically significant change backed up by the literature or current guidelines.

Dyspnea and exercise limitation in patients with advanced emphysema are partially attributed to static and dynamic hyperinflation of the lungs $[4,5]$. As the therapeutic options for patients with severe emphysema are limited, a surgical lung volume reduction initially raised hopes to address this issue; however, it is associated with
Eberhardt et al. 
crucial morbidity and mortality rates [13]. Recently ELVR techniques have been shown to be efficient in decreasing hyperinflation, thus offering the benefits of LVRS without the associated morbidity [18-21]. ELVR by means of EBV placement is the most commonly used method. This pilot study supports the idea that this procedure may be pathophysiologically and clinically useful in selected patients of COPD and PH.

\section{Possible Mechanism of Hemodynamic and Clinical Improvement by ELVR}

After 90 days, we observed a decrease in the mean PAWP and to a lesser extent in mPAP. The mean right atrial pressure (RAP) and the initially elevated mean right atrial area measured by echocardiography decreased as well. We assume that the pathophysiological mechanism involved might be an improvement in static and dynamic hyperinflation by ELVR, leading to a decrease in intrathoracic pressure and consequently enhancing the impaired left ventricular filling. This hypothesis is supported by the findings of Barr et al. [33], who documented a linear association between the degree of airflow obstruction and hemodynamic changes which was even present in mild COPD. Airflow obstruction and hyperinflation were related to impaired left ventricular filling, a reduced stroke volume, and a lower CO [34]. In severe COPD, hyperinflation may cause the intrathoracic pressure to exceed the venous pressure and thus compromise the filling volumes of both ventricles $[34,35]$. Enhanced filling of the right ventricle due to a reduction of hyperinflation after ELVR may lead to a decrease in RAP and thereby to a decrease in right atrial size. In the National Emphysema Treatment Trial (NETT) increased PAWP and left ven- tricular end-diastolic pressures were reported preoperatively, and the PAWP decreased after LVRS [36, 37]. These findings are in accordance with the results of our study. We suggest that an elevated PAWP at baseline does not necessarily imply the existence of a left heart disease and could also be caused by hyperinflation and thereby impaired left- or biventricular filling with associated pulmonary venous congestion.

\section{Limitations}

Beside the limitations mentioned above, this study was limited by the low patient number and the lack of a control group.

\section{Conclusion}

To our knowledge, this is the first prospective pilot study to evaluate the effect of ELVR in patients with severe COPD, lung emphysema, and concomitant $\mathrm{PH}$. ELVR was feasible and resulted, after 3 months, in marked improvement of clinical and hemodynamic parameters in 5 out of 6 patients. Thus, this treatment may be an interesting new perspective for selected COPD-PH patients. Further larger-scale and controlled studies are needed to confirm these results and to detect those COPD-PH patients who might benefit from ELVR.

\section{Financial Disclosure and Conflicts of Interest}

All of the authors report no conflicts of interest related to the data in this paper.

\section{References}

1 Lozano R, Naghavi M, Foreman K, et al: Global and regional mortality from 235 causes of death for 20 age groups in 1990 and 2010: a systematic analysis for the Global Burden of Disease Study 2010. Lancet 2013;380:20952128.

-2 Rabe KF, Hurd S, Anzueto A, Barnes PJ, Buist SA, Calverley P, Fukuchi Y, Jenkins C, Rodriguez-Roisin R, van Weel C, Zielinski J: Global strategy for the diagnosis, management, and prevention of chronic obstructive pulmonary disease: GOLD executive summary. Am J Respir Crit Care Med 2007;176:532-555.

$\checkmark 3$ Celli BR: Update on the management of COPD. Chest 2008;133:1451-1462.

4 Ofir D, Laveneziana P, Webb KA, Lam YM, O’Donnell DE: Mechanisms of dyspnea dur- ing cycle exercise in symptomatic patients with GOLD stage I chronic obstructive pulmonary disease. Am J Respir Crit Care Med 2008; 177:622-629.

5 O'Donnell DE, Revill SM, Webb KA: Dynamic hyperinflation and exercise intolerance in chronic obstructive pulmonary disease. Am J Respir Crit Care Med 2001;164:770-777.

6 Galie N, Hoeper MM, Humbert M, Torbicki A, Vachiery JL, Barbera JA, Beghetti M, Corris $\mathrm{P}$, Gaine S, Gibbs JS, Gomez-Sanchez MA, Jondeau G, Klepetko W, Opitz C, Peacock A, Rubin L, Zellweger M, Simonneau G; ESC Committee for Practice Guidelines: Guidelines for the diagnosis and treatment of pulmonary hypertension: the Task Force for the Diagnosis and Treatment of Pulmo- nary Hypertension of the European Society of Cardiology (ESC) and the European Respiratory Society (ERS), endorsed by the International Society of Heart and Lung Transplantation (ISHLT). Eur Heart J 2009; 30:2493-2537.

7 Chatila WM, Thomashow BM, Minai OA, Criner GJ , Make BJ: Comorbidities in chronic obstructive pulmonary disease. Proc Am Thorac Soc 2008;5:549-555.

8 Falk JA, Kadiev S, Criner GJ, Scharf SM, Minai OA, Diaz P: Cardiac disease in chronic obstructive pulmonary disease. Proc Am Thorac Soc 2008;5:543-548.

9 Chaouat A, Naeije R, Weitzenblum E: Pulmonary hypertension in COPD. Eur Respir J 2008;32:1371-1385.
ELVR with EBV in Patients with Severe Emphysema and Established $\mathrm{PH}$ 
10 Scharf SM, Iqbal M, Keller C, Criner G, Lee S, Fessler HE; National Emphysema Treatment Trial Group: Hemodynamic characterization of patients with severe emphysema. Am J Respir Crit Care Med 2002;166:314-322.

11 Hyduk A, Croft JB, Ayala C, Zheng K, Zheng ZJ, Mensah GA: Pulmonary hypertension surveillance - United States, 1980-2002. MMWR Surveill Summ 2005;54:1-28.

$\checkmark 12$ Minai OA, Chaouat A, Adnot S: Pulmonary hypertention in COPD: epidemiology, significance, and management - pulmonary vascular disease: the global perspective. Chest 2010; 137:39S-51S.

13 Fishman A, Martinez F, Naunheim K, Piantadosi S, Wise R, Ries A, Weinmann G, Wood DE; National Emphysema Treatment Trial Research Group: A randomized trial comparing lung volume-reduction surgery with medical therapy for severe emphysema. N Engl J Med 2003;348:2059-2073.

-14 Sciurba FC, Rogers RM, Keenan RJ, Slivka WA, Gorcsan J 3rd, Ferson PF, Holbert JM, Brown ML, Landreneau RJ: Improvement in pulmonary function and elastic recoil after lung-reduction surgery for diffuse emphysema. N Engl J Med 1996;334:1095-1099.

15 Criner GJ, Cordova FC, Furukawa S, Kuzma AM, Travaline JM, Leyenson V, O'Brien GM: Prospective randomized trial comparing bilateral lung volume reduction surgery to pulmonary rehabilitation in severe chronic obstructive pulmonary disease. Am J Respir Crit Care Med 1999;160:2018-2027.

16 Gasparini S, Zuccatosta L, Bonifazi M, Bolliger CT: Bronchoscopic treatment of emphysema: state of the art. Respiration 2012;84: 250-263.

$\checkmark 17$ Sciurba FC, Ernst A, Herth FJ, Strange C, Criner GJ, Marquette $\mathrm{CH}$, Kovitz KL, Chiacchierini RP, Goldin J, McLennan G; VENT Study Research Group: A randomized study of endobronchial valves for advanced emphysema. N Engl J Med 2010;363:1233-1244.

-18 Wan IY, Toma TP, Geddes DM, Snell G, Williams T, Venuta F, Yim AP: Bronchoscopic lung volume reduction for end-stage emphysema: report on the first 98 patients. Chest 2006;129:518-526.

19 Springmeyer SC, Bolliger CT, Waddell TK, Gonzalez X, Wood DE; IBV Valve Pilot Trials Research Teams: Treatment of heterogeneous emphysema using the spiration IBV valves. Thorac Surg Clin 2009;19:247-253.
20 Sterman DH, Mehta AC, Wood DE, Mathur PN, McKenna RJ Jr, Ost DE, Truwit JD, Diaz P, Wahidi MM, Cerfolio R, Maxfield R, Musani AI, Gildea T, Sheski F, Machuzak M, Haas AR, Gonzalez HX, Springmeyer SC; IBV Valve US Pilot Trial Research Team: A multicenter pilot study of a bronchial valve for the treatment of severe emphysema. Respiration 2010;79:222-233.

21 Toma TP, Hopkinson NS, Hillier J, Hansell DM, Morgan C, Goldstraw PG, Polkey MI, Geddes DM: Bronchoscopic volume reduction with valve implants in patients with severe emphysema. Lancet 2003;361:931-933.

22 Vestbo J, Hurd SS, Agusti AG, Jones PW, Vogelmeier C, Anzueto A, Barnes PJ, Fabbri LM, Martinez FJ, Nishimura M, Stockley RA, Sin DD, Rodriguez-Roisin R: Global strategy for the diagnosis, management, and prevention of chronic obstructive pulmonary disease: GOLD executive summary. Am J Respir Crit Care Med 2013;187:347-365.

23 Koenigkam-Santos M, Puderbach M, Gompelmann D, Eberhardt R, Herth F, Kauczor $\mathrm{HU}$, Heussel CP: Incomplete fissures in severe emphysematous patients evaluated with MDCT: incidence and interobserver agreement among radiologists and pneumologists. Eur J Radiol 2012;81:4161-4166.

24 Thurnheer R, Engel H, Weder W, Stammberger U, Laube I, Russi EW, Bloch KE: Role of lung perfusion scintigraphy in relation to chest computed tomography and pulmonary function in the evaluation of candidates for lung volume reduction surgery. Am J Respir Crit Care Med 1999;159:301-310.

25 Heussel CP, Achenbach T, Buschsieweke C, Kuhnigk J, Weinheimer O, Hammer G, Duber C, Kauczor HU: Quantification of pulmonary emphysema in multislice-CT using different software tools. Rofo 2006;178:987-998.

26 Grunig E, Barner A, Bell M, Claussen M, Dandel M, Dumitrescu D, Gorenflo M, Holt S, Kovacs G, Ley S, Meyer JF, Pabst S, Riemekasten G, Saur J, Schwaiblmair M, Seck C, Sinn L, Sorichter S, Winkler J, Leuchte HH: Noninvasive diagnosis of pulmonary hypertension: ESC/ERS guidelines with updated commentary of the Cologne Consensus Conference 2011. Int J Cardiol 2011;154(suppl 1): S3-S12.

27 Mahler DA, Wells CK: Evaluation of clinical methods for rating dyspnea. Chest 1988;93: 580-586.
28 Jones PW, Quirk FH, Baveystock CM, Littlejohns P: A self complete measure of health status for chronic airflow limitation - the St. George's Respiratory Questionnaire. Am Rev Respir Dis 1992;145:1321-1327.

29 Yock PG, Popp RL: Noninvasive estimation of right ventricular systolic pressure by Doppler ultrasound in patients with tricuspid regurgitation. Circulation 1984;70:657-662.

30 Hoeper MM, Andreas S, Bastian A, Claussen M, Ghofrani HA, Gorenflo M, Grohe C, Gunther A, Halank M, Hammerl P, Held M, Kruger S, Lange TJ, Reichenberger F, Sablotzki A, Staehler G, Stark W, Wirtz H, Witt C, Behr J: Pulmonary hypertension due to chronic lung disease: updated recommendations of the $\mathrm{Co}$ logne Consensus Conference 2011. Int J Cardiol 2011;154(suppl 1):S45-S53.

31 Donohue JF: Minimal clinically important differences in COPD lung function. COPD 2005;2:111-124.

32 Jones PW: St. George's Respiratory Questionnaire: MCID. COPD 2005;2:75-79.

33 Barr RG, Bluemke DA, Ahmed FS, Carr JJ, Enright PL, Hoffman EA, Jiang R, Kawut SM, Kronmal RA, Lima JA, Shahar E, Smith LJ, Watson KE: Percent emphysema, airflow obstruction, and impaired left ventricular filling. N Engl J Med 2010;362:217-227.

34 Jorgensen K, Muller MF, Nel J, Upton RN, Houltz E, Ricksten SE: Reduced intrathoracic blood volume and left and right ventricular dimensions in patients with severe emphysema: an MRI study. Chest 2007;131:10501057.

-35 Watz H, Waschki B, Meyer T, Kretschmar G, Kirsten A, Claussen M, Magnussen H: Decreasing cardiac chamber sizes and associated heart dysfunction in COPD: role of hyperinflation. Chest 2010;138:32-38.

36 Criner GJ, Scharf SM, Falk JA, Gaughan JP, Sternberg AL, Patel NB, Fessler HE, Minai OA, Fishman AP; National Emphysema Treatment Trial Research Group: Effect of lung volume reduction surgery on resting pulmonary hemodynamics in severe emphysema. Am J Respir Crit Care Med 2007;176: 253-260.

37 Jorgensen K, Houltz E, Westfelt U, Nilsson F, Schersten H, Ricksten SE: Effects of lung volume reduction surgery on left ventricular diastolic filling and dimensions in patients with severe emphysema. Chest 2003;124:18631870. 